\title{
Current-mode CMOS Active Inductor with Applications to Low-Voltage Oscillators
}

\author{
Minglin Ma \\ Key Laboratory of Intelligent \\ Computing \& Information \\ Processing of Ministry of Education, \\ Xiangtan University, China \\ minglin_ma@xtu.edu.cn
}

\author{
Zhijun Li \\ Key Laboratory of Intelligent \\ Computing \& Information \\ Processing of Ministry of Education, \\ Xiangtan University, China \\ lizhijun_320@163.com
}

\author{
Zili Yao \\ Key Laboratory of Intelligent \\ Computing \& Information \\ Processing of Ministry of Education, \\ Xiangtan University, China \\ yaozili@xtu.edu.cn
}

\begin{abstract}
This paper investigates a current mode active inductor. In the proposed active inductor, three current mirrors have been connected to each other to realize the negative feedback. This active conductor has a two layer transistor structure. A $4.257 \mathrm{GHz}, 1.2-\mathrm{V}$ power supply non-inductive LC negative resistor oscillator, base on two of the proposed active inductors, is demonstrated.
\end{abstract}

Keywords-active inductor; current mirror; low-voltage

\section{INTRODUCTION}

Wireless and mobile communications are two of the fastest growing microelectronics applications and have an enormous impact on everyday life. Driven by the insatiable demand for lower cost, lower power and higher data rates in wireless and mobile communications systems, a growing demand for CMOS wireless System-on-a-Chip(SoC) solutions is recorded. This trend has motivated the evolution and research on low voltage, low power, low cost RFIC designs [1, 2].

The oscillator is an important building block in RF transceivers. Inductive characteristics are critically needed in LC tank oscillators to realize frequency selection. Traditionally, passive inductors are off-chip discrete components. The need for off-chip communications with these passive components severely reduces the reliability, and increases the cost. CMOS active inductors have been widely used in the design of ring and LC tank oscillators because of their small chip area and wide tenability [3-6].

All these circuits [3-6] suffer from a tradeoff between low voltage and low cost. Here, we propose a LC oscillator based on the current mode active inductor. Current mode approach has several advantages, such as extended bandwidth, simple circuit structure, higher dynamic range, suitability of operation in reduced power supply environment, low power consumption, low voltage operation [7-12].

In the next section, the current mode active inductor is introduced and analyzed. In section III, an LC oscillator based on the active inductor is described. Section IV is the conclusion.

\section{THE PROPOSED ACTIVE INDUCTOR}

The active inductor proposed is depicted in Figure 1. It is based on three current mirrors $\left(\mathrm{M}_{1,2}, \mathrm{M}_{3,4}, \mathrm{M}_{5,6}\right)$. $\mathrm{I}_{\mathrm{O}}$ is the bias current. Consider the equivalent network shown in Figure 2 where a current mirror can be equivalent to a trans-impedance $\left(\mathrm{T}_{\mathrm{i}}\right)$ and a trans-conductance $\left(\mathrm{g}_{\mathrm{m}}\right) \cdot \mathrm{G}_{\mathrm{o} 1}$ and $\mathrm{G}_{\mathrm{O} 2}$ denote the total conductances at nodes 1 and 2 respectively. Note that $G_{01}$ is due to the finite output impedance of the $g_{\mathrm{m} 1}$ and the finite input impedance of $\mathrm{T}_{\mathrm{i} 2}$. $\mathrm{C}_{1,2}$ are the parasitic capacitors.

The following equations apply:

$$
\left.\begin{array}{c}
\left.\left(s C_{1}+G o_{1}\right) V_{1}=-V_{2} g_{m 1} \quad \text { (node } 1\right) \\
\left(s C_{2}+G o_{2}\right) V_{2}-V_{1} g_{m 2} T_{i 3} g_{m 3}=I_{i n} \quad(\text { node } 2)
\end{array}\right\}
$$

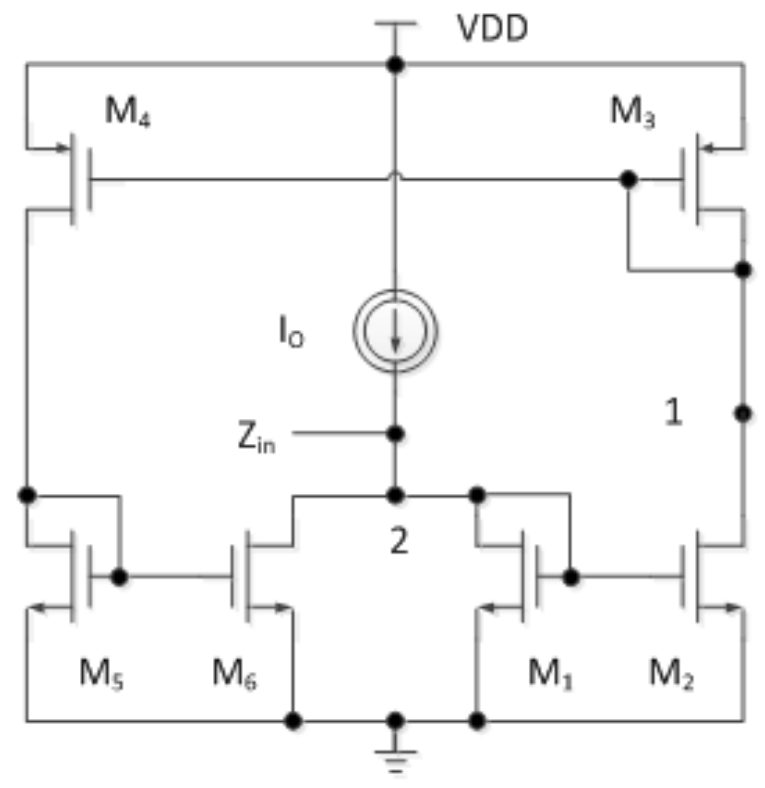

Fig. 1. Proposed current mode active inductor 


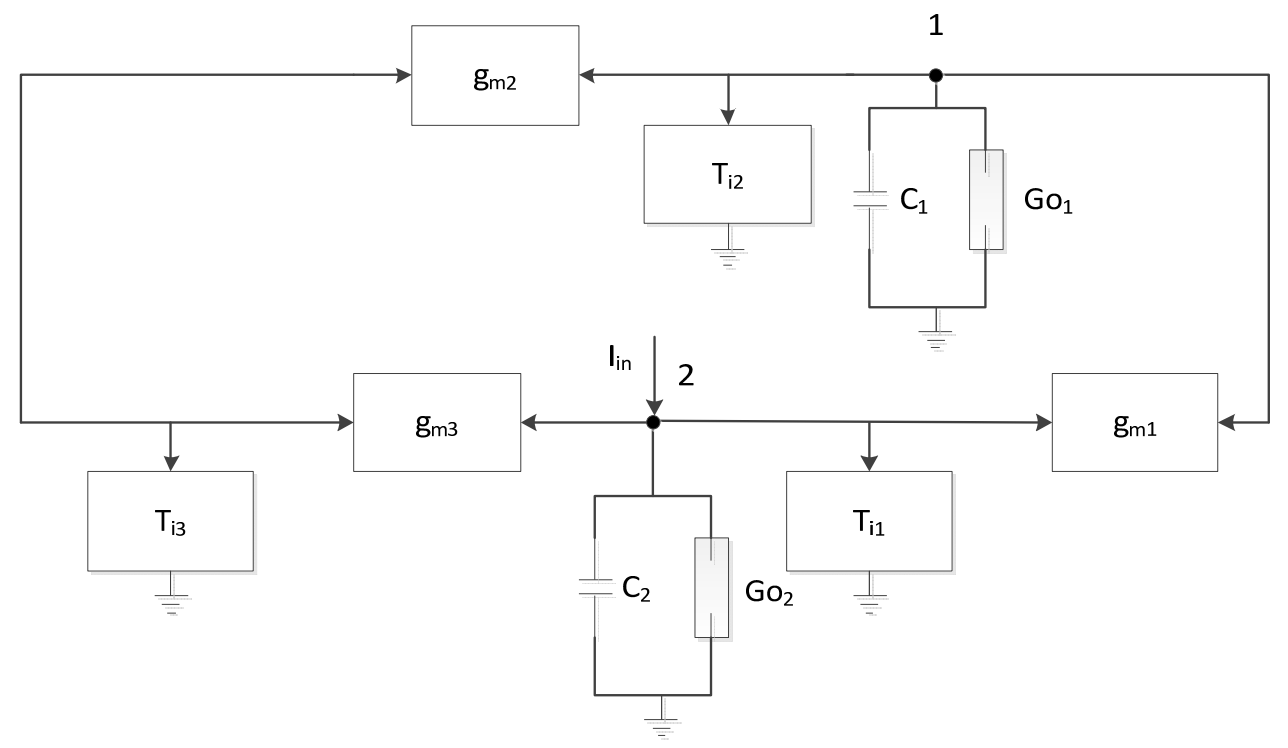

Fig. 2. equivalent network of the current mode active inductor

The admittance looking into port 2 of the equivalent network is obtained from

$$
Y=\frac{I_{\text {in }}}{V_{2}}=s C_{2}+G o_{2}+\frac{1}{s \frac{C_{1}}{g_{m 1} g_{m 2} T_{i 3} g_{m 3}}+\frac{G o_{1}}{g_{m 1} g_{m 2} T_{i 3} g_{m 3}}}
$$

Equation (2) can be represented by the RLC networks shown in Figure 3 with parameters given by:

$$
R_{p}=\frac{1}{G o_{2}}, C_{p}=C_{2}, R_{s}=\frac{G o_{1}}{g_{m 1} g_{m 2} T_{i 3} g_{m 3}}, L=\frac{C_{1}}{g_{m 1} g_{m 2} T_{i 3} g_{m 3}}
$$

The proposed circuit contains only three current mirrors that all are of a two layer transistor structure. The minimum voltage required for proper circuit operation is $\mathrm{V}_{\mathrm{gs}}+\mathrm{V}_{\mathrm{dsat}}$ where $\mathrm{V}_{\mathrm{dsat}}$ is the minimum $\mathrm{V}_{\mathrm{ds}}$ voltage required to keep a MOS transistor in saturation. The compactness of the circuit results in low voltage supply and low power consumption.

The active inductor has been simulated in Cadence (5.10.41_USR6.12) using parameters for chartered $0.18 \mu \mathrm{m} \mathrm{RF}$ CMOS Process with VDD $=1.2 \mathrm{~V}$. All transistors have the same channel length of $0.18 \mu \mathrm{m}$. The width of the transistors and the value of $\mathrm{I}_{\mathrm{o}}$ were chosen as $\mathrm{W}_{1}=10, \mathrm{~W}_{2}=30, \mathrm{~W}_{3}=40$, $\mathrm{W}_{4}=120, \mathrm{~W}_{5}=30, \mathrm{~W}_{6}=42.85, \mathrm{I}_{\mathrm{o}}=3 \mathrm{~mA}$. The simulated $\operatorname{Im}(Z)$ and $\operatorname{Re}(Z)$ is shown in Figure 4. $\mathrm{Q}_{\text {Lmax }}=7.8$ is achieved at 4.257 GHz.

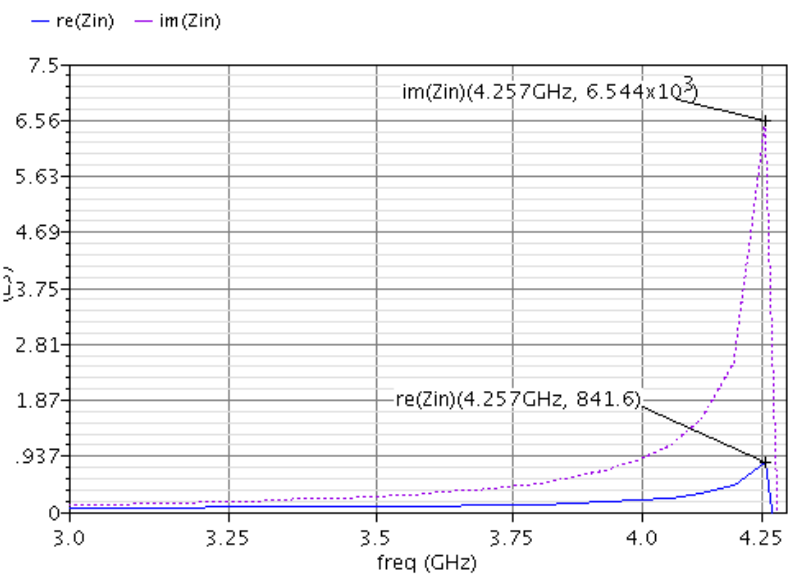

Fig. 4. Simulated $\operatorname{Im}(Z)$ and $\operatorname{Re}(Z)$
Fig. 3. The admittance looking into port 2

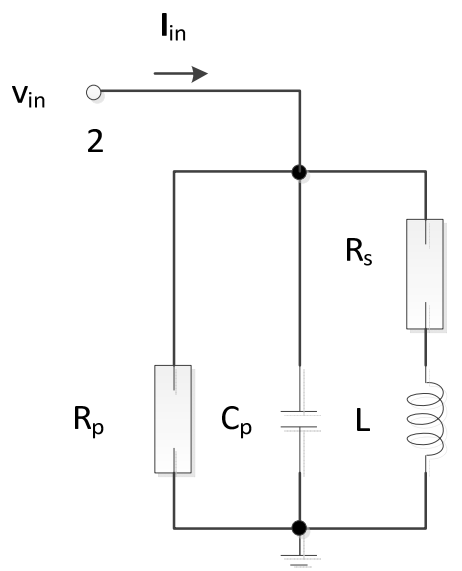




\section{AN LC-TANK OSCILLATORS USING THE PROPOSED ACTIVE INDUCTORS}

The proposed low-voltage current mode active inductor is applied to LC oscillator shown in Figure 5. This LC oscillator consists of two active inductors. The capacitor of the LC tank is the parasitic capacitors of transistors. The negative resistor, which is used to cancel the input resistance of the active inductors, is realized by the cross coupling between $\mathrm{M}_{7}$ and $\mathrm{M}_{27}$.

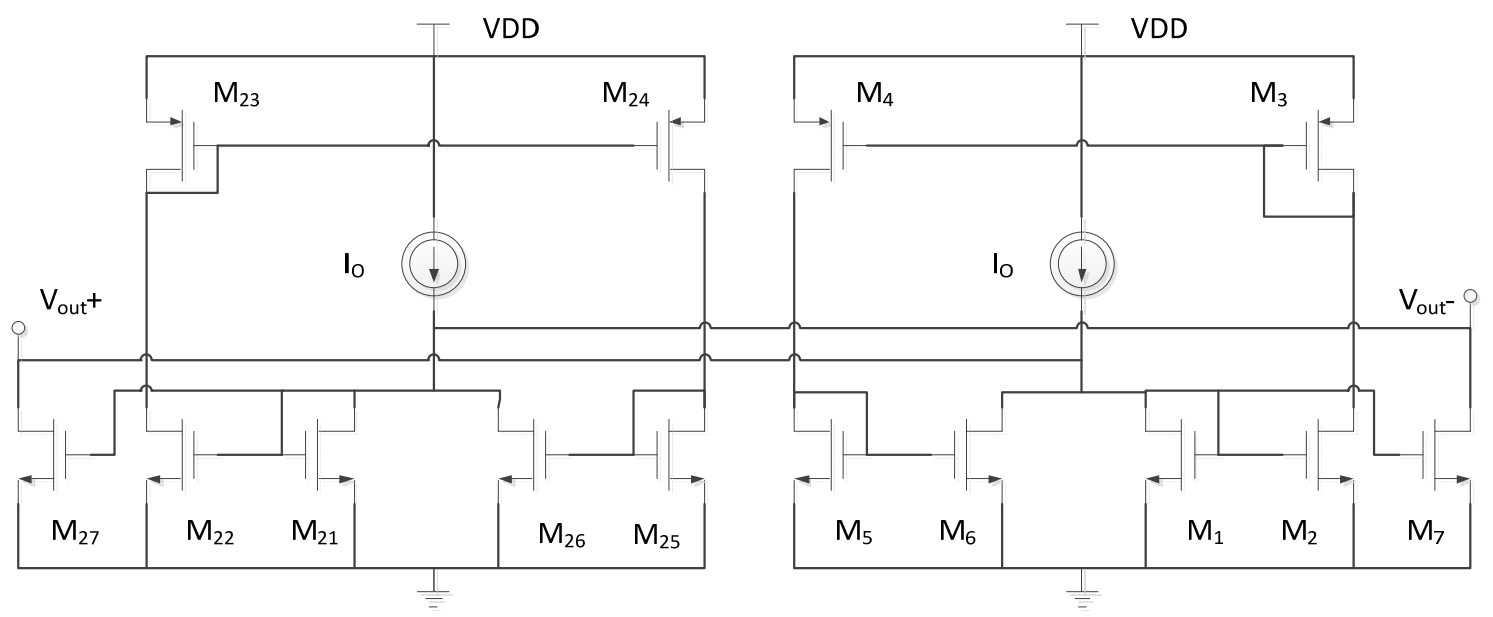

Fig. 5. Current mode LC oscillator based on the active inductor

Figure 6 shows the output voltage of the LC oscillator shown in Figure 5. Its frequency is set to about $4.257 \mathrm{GHz}$. Spectre from Cadence design systems is used for the phase noise simulation. It is approximately $-105 \mathrm{dBc} / \mathrm{Hz}(1 \mathrm{MHz}$ frequency offset). Figure 7 shows the simulated phase noise. Table I lists the comparison of the performance of previous active inductors oscillators to the one proposed in this paper.

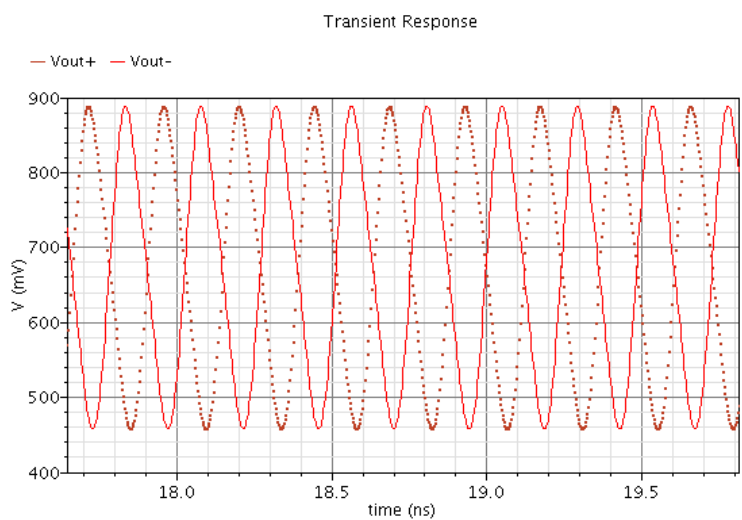

Fig. 6. The output voltage of the proposed oscillator

TABLE I. COMPARISON OF ACTIVE INDUCTOR OSCILLATORS PERFORMANCE

\begin{tabular}{|c|c|c|c|c|c|}
\hline Ref. & $\begin{array}{c}\text { Tech. } \\
(\boldsymbol{\mu m})\end{array}$ & Vdd & Phase noise & $\begin{array}{c}\text { PDC } \\
(\mathbf{m W})\end{array}$ & $\begin{array}{c}\text { F } \\
(\mathbf{G H z})\end{array}$ \\
\hline$[3]$ & 0.18 & $1.8 \mathrm{~V}$ & $-101 \sim-118$ & $6-28$ & 3 \\
\hline$[4]$ & 0.18 & $1.8 \mathrm{~V}$ & 110 & 30 & 1.6 \\
\hline$[5]$ & 0.18 & $1.8 \mathrm{~V}$ & -122.9 & ---- & 1.6 \\
\hline$[6]$ & 0.18 & $1.8 \mathrm{~V}$ & -109.4 & 30.5 & 1.5 \\
\hline This work & 0.18 & $1.2 \mathrm{~V}$ & $-105 \mathrm{t}$ & 20 & 4.257 \\
\hline
\end{tabular}

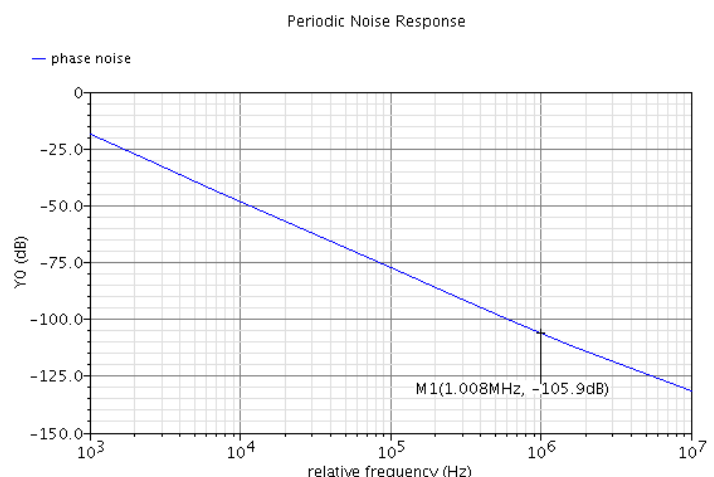

Fig. 7. The simulated phase noise at the oscillation frequency of $4.257 \mathrm{GHz}$

\section{CONCLUSION}

This paper proposes a current mode active inductor build with three current mirrors. A $4.257 \mathrm{GHz}, 1.2-\mathrm{V}$ power supply, LC negative resistor oscillator, based on the proposed active inductor, is also demonstrated. Considering that the phase noise of the oscillator is approximately $-105 \mathrm{dBc} / \mathrm{Hz}$ at $1 \mathrm{MHz}$ frequency offset, it is hinted that it can be used in a current domain circuit or a voltage domain circuit with low-voltage supply and small size.

\section{ACKNOWLEDGMENT}

This work was financially supported by a subproject of the Nature Science Foundation of China (No. 11KH|KH01069), the Nature Science Foundation of China(No. 61176032), and a project supported by the Scientific Research Fund of Hunan Provincial Education Department (NO. 12C0417) 


\section{REFERENCES}

[1] M. Saito, M. Ono, R. Fujimoto, H. Tanimoto, N. Ito, T. Yoshitomi, T. Ohguro, H. S. Momose, H. Iwai, "0.15- $\mu \mathrm{m}$ RF CMOS technology compatible with logic CMOS for low-voltage operation", IEEE Transactions on Electron Devices, Vol. 45, No. 3, pp. 737 -742, 1998

[2] D. Wang, J. Ou, X. Wang; "RF Design Challenges at 90nm RFCMOS Technology Under Low Voltage Applications", ICSICT İ06. 8th International Conference on Solid-State and Integrated Circuit Technology, pp. $1522-1525$, Shanghai, 2006

[3] L. Lu, H. Hsieh, Y. Liao, "A wide tuning-range CMOS VCO with a differential tunable active inductor", IEEE Transactions on Microwave Theory and Techniques, Vol. 54, No. 9, pp. 3462-3468, 2006

[4] A. Tang, F. Yuan, E. Law, "A new CMOS active transformer QPSK modulator with optimal bandwidth control", IEEE Transactions on Circuits and Systems II: Express Briefs, Vol. 55, No. 1, pp. 11-15, 2008

[5] A. Tang, F. Yuan, E. Law, "Class AB CMOS active transformers Voltage-Controlled Oscillators", ISSSE '07, International Symposium on Signals, Systems and Electronics, pp. 501-504, Montreal, 2007

[6] A. Tang, F. Yuan, E. Law, "Low-noise CMOS active transformer voltage-controlled oscillators", MWSCAS 50th Midwest Symposium on Circuits and Systems, pp. 1441-1444, Montreal, 2007

[7] T. H. Lee, "The design of CMOS radio-frequency integrated circuits", Cambridge University Press, 2003 